\title{
Origin and Distribution of Polycyclic Aromatic Hydrocarbons in Lagoon Ecosystems of Morocco
}

\author{
Abdelghani Semlali ${ }^{*}$, Abdelghani Chafik $^{1}$, Mohamed Talbi ${ }^{2}$ and Hélène Budzinski ${ }^{3}$ \\ ${ }^{I}$ Institut National de Recherches Halieutique, Morocco \\ ${ }^{2}$ Department of Chemistry, University of Hassan II, Morocco \\ ${ }^{3}$ Laboratoire de Physico- et Toxico-Chimie de l'Environnement (LPTC) Université de Bordeaux 1, France
}

\begin{abstract}
Polycyclic Aromatic Hydrocarbons (PAHs) were determined in sediments and bivalves by the Gas chromatography coupled to Mass spectrometer (GC/MS). PAHs concentrations in sediments of My Bousselham and Khnifiss, Atlantics lagoons, (expressed as $\sum \mathrm{PAH}$ ) ranged from 31 to $82 \mathrm{ng} / \mathrm{g}$ of dry weight and from 6.6 to $34 \mathrm{ng} / \mathrm{g}$ of dry weight, respectively. Concerning organisms, PAHs levels contamination ranged from 28 to $117 \mathrm{ng} / \mathrm{g}$ of dry weight for My Bousselham (Ruditapes Decussates) and from 7 to $18.5 \mathrm{ng} / \mathrm{g}$ of dry weight for Khnifiss Lagoon Oyster (Crassostrea gigas). In the Med Lag (Nador), the results obtained showed a range varying from 6 to $126 \mathrm{ng} / \mathrm{g}$ of dry weight for sediments and from 24 to $32 \mathrm{ng} / \mathrm{g}$ of dry weight for organisms (Mytilus Galoprovincialis). The origin investigation of PAHs in sediment revealed, that the process of combustion was the main source in these Lagoons, while the diagenetic source, related to the high concentrations obtained of Perylene, was established only in both Atlantics Lagoons (Khnifiss and My Bousselham).

A prevalence of high molecular weight PAHs was observed, with a considerable predominance of 4-ring PAHs in sediments and organisms of the My bousselham and Nador lagoons, while, no clear predominance was observed in the compartments studied in the Khnifiss lagoon.

Correlation study of individual PAH between sediments and organisms, showed that absorption by Clams of low molecular weight PAH group, of which correlation was low, could be done through the water dissolved form, while the absorption of heavier molecular weight PAHs, which showed a high correlation of their distribution between sediments and Clams, could be the absorption from particulate matter.
\end{abstract}

Keywords: PAHs, Lagoons, Molluscs, Sediments, Molecular ratios.

\section{INTRODUCTION}

Polycyclic Aromatic Hydrocarbons are among the pollutants most monitored in marine environment, particularely in higly stressed areas such as harbours, estuaries, and others shallow coastal zones exposed to anthropogenic inputs and natural emissions, because are widespread class of environmental chemicals pollutants contaminants in marine environment. Among anthropogenic factors, petrogenic and pyrolytic sources are the most important. Whereas pyrolytic sources, which are largely prevalent in aquatic environment, include combustion processes (e.g., fossil fuel combustion forests fires, shrub and grass fires), the petrogenic input is closely related to petroleum products (e.g., oil spills, road construction materials) [1]. This class of compounds has been widely studied, because of its carcinogenic and mutagenic character [2]. Due to their hydrophobic character, which increases with molecular weight [3], these neutral compounds tend to rapidly adsorb to sediment particles, and therefore represent the most important reservoir of PAHs in marine environment. For that reason, sediments are of high interest in environmental assessment of aquatic ecosystems

*Address correspondence to this author at the Institut National de Recherches Halieutique, Morocco; Tel: 212-5-39946586/87; Fax: 212-539325139; E-mail: a_semabd@yahoo.com and can represent a useful tool for monitoring inputs of PAHs in coastal areas. The fate of PAHs in water is strongly influenced by sorption mechanisms between water and the solid phase, of which physicochemical properties may play a critical role in sorption [4]. Furthermore, sources exhibit different chemical behaviours and distribution in marine sediments. In order to distinguish between these two origins, some molecular ratios of specific hydrocarbons were developed, based on the thermodynamic stability of isomers [5-8]. Also the use of marine organisms, especially, as bioindicators of chemical pollution, was developed for pollution monitoring programs such as the "Mussel Watch" in the USA or the O.N.N (Observation Network National) in French, which use Mussels and Oysters to study spatial and temporal trends in coastal and estuaries zones [9-11].

This preliminary work focus on the presence, distribution, and origin of several PAHs (those highlighted by the US-EPA) in superficial sediments and bivalve's molluscs collected of three lagoons, which represent wetlands of particularly ecological and economic relevance in Morocco, and previously not studied. Two are located at Atlantic coast (Khnifiss and My Bousselham Lagoons) and the other one, in the Mediterranean coast (Nador Lagoon). Moreover, we have studied the processes affecting the introduction of these pollutants in these aquatic ecosystems, being an important 
aspect for different decision makers in social and economical affairs. Besides, the establishment of the referential state of contamination by these pollutants in these high vulnerable ecosystems is very important, because Coastal's areas of Morocco are highly exposed to a potential traffic of petroleum tankers, especially the Mediterranean coastline.

\section{MATERIALS AND METHODOLOGY}

\subsection{Study Areas}

The Nador Lagoon is located on the Moroccan eastern coast. It is a restricted Lagoon of $115 \mathrm{~km}^{2}(25 \times 7.5 \mathrm{~km})$ and with a depth not exceeding $8 \mathrm{~m}$. The island barrier is $25 \mathrm{~km}$ large with an average width of $300-400 \mathrm{~m}$ (it can come up to $2 \mathrm{~km}$ in some parts) and is cut by an artificial inlet. The Lagoon is nourished by several tributaries which are used today for the sewer discharge of the upstream built-up areas. There are 3 urban clusters in the surroundings and 2 saline workings on the banks of the Lagoon.

Situated on the Atlantic coast of Morocco, My bousselham Lagoon is located about $150 \mathrm{Km}$ of the North of the Capital Rabat, and about $40 \mathrm{Km}$ South of Larach. Its area is around $30 \mathrm{~km}^{2}$, but divided into two areas by the Drader channel, Merja Kahla in the North and the Merja Zarga in the South. It's considered as an important site of biological and ecological interest.

Khnifiss Lagoon, situated in the South of the Atlantic coast of Morocco (20 Km long and $65 \mathrm{Km}^{2}$ surface area), between Tarfaya and Tantan $\left(28^{\circ} 02^{\prime} 54^{\prime \prime} \mathrm{N}-12^{\circ} 13^{\prime}\right.$ 66 "W). This lagoonis a potentiel site for aquaculture and tourism, if planned with ecological awarness. It opens up to the Atlantic Ocean by a narrow inlet, about $100 \mathrm{~m}$ wide. The large surface area of the Lagoon and it's high bilogical production of the avifaune, qualify it among the sites concerned by the RAMSAR convention for humid zone conservation.

\subsection{Sampling}

The sampling operations took place in 2006, during the months of June, July, and August, for My Bousselham,
Khnifiss and Nador Lagoon, respectively. In each sampling station (shown in Fig. 1), superficial sediment $(0-2 \mathrm{~cm})$ was collected by diving, and transferred to aluminium container for all Lagoons. Nador Lagoon Mussels (Mytilus Galoprovincialis) and Khnifiss Oysters (Crassostrea gigas) were collected by diving while the My Bousselham clams (Ruditapes Decussates) were collected by hand. After dissection, these organisms were also transferred to aluminium containers. Both containers were put in a plastic bag and frozen at $-20^{\circ} \mathrm{C}$.

\subsection{Samples Preparation}

About $0.5 \mathrm{~g}$ of freeze-dried organisms and sediments sieved at $63 \mu \mathrm{m}$, were extracted with Methylene Chloride, using microwave assisted extraction with a Maxi-digest 350 apparatus, at $30 \mathrm{~W}$ for $10 \mathrm{~min}$. The organic extract was then reduced to a small volume using a rotary evaporator. Then the extract was purified into a micro-column containing alumina $(1.5 \mathrm{~g})$ by eluting with Methylene Chloride. This purified extract was then fractioned on a micro column containing silica $(0.8 \mathrm{~g})$ for organisms; and silica and activated cooper for sediment, in order to collect separately saturated and aromatic compounds, eluted with respectively pentane and a mixture of Pentane: Methylene Chloride $(65: 35 ; \mathrm{v}: \mathrm{v})$. Activated cooper was used to eliminate the sulphur from the organic extract. The purified aromatic fraction was finally concentrated to a few $\mu l$ in iso-octane and analysed by gas chromatography coupled to a mass spectrometer (GC/MS).

In these samples, the PAHs studied are: Phenanthrene (Phe), Anthracene (An), Acenaphthene (Ace), Acenaphthylene (Acy), Fluorene (F), Fluoranthene (Fl), Pyrene (Py), Chrysene (Chry), Benzo [a] Anthracene (B[a]A), Benzo $[\mathrm{b} ; j ; k]$ Fluoranthene $(\mathrm{B}[\mathrm{b} ; \mathrm{j} ; \mathrm{k}] \mathrm{F})$, Benzo [a] Pyrene (B[a]P), Indeno [1,2,3-cd] Pyrene [IP], Benzo [ghi] Perylene (BP), Dibenzo [a,h] Anthracene (D[ah]A). This group of PAHs was identified by the U.S Environment Protection Agency (US-EPA), as priority pollutants to be monitoring in marine environments. Naphthalene was not considered because of its high volatility. [b;j;k] isomers of Benzo-Fluoranthene were grouped, because of their poor separation (coelution).

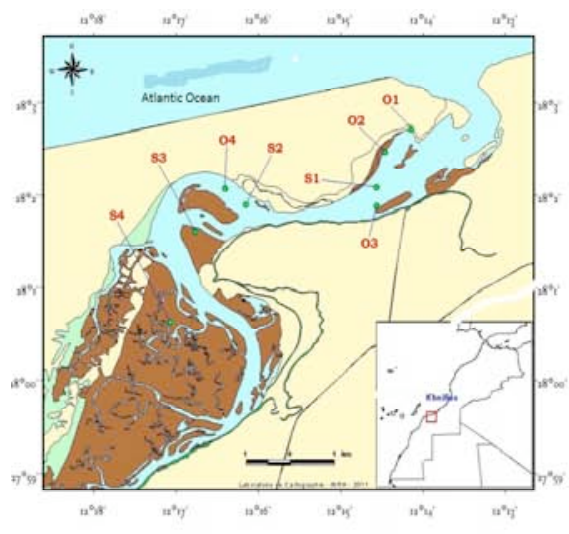

(a)

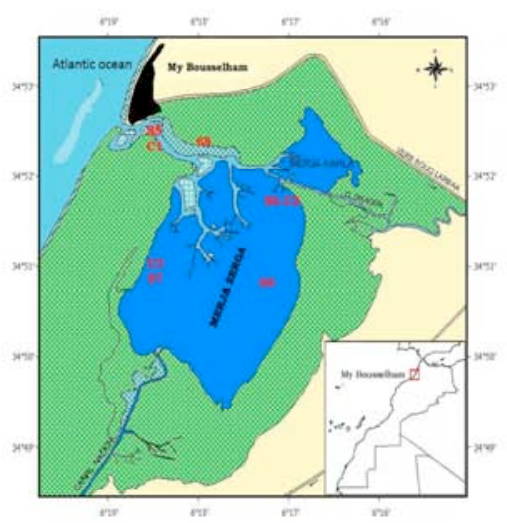

(b)

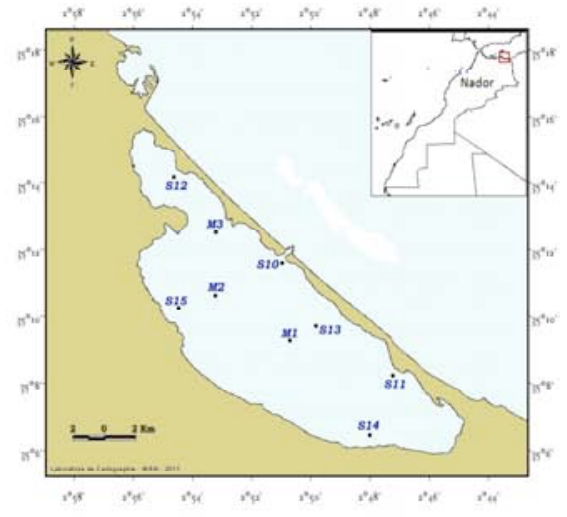

(c)

Fig. (1). Study area and location of sampling sites of sediments and organisms. (a) Khnifiss Lagoon; (b) My bousselham Lagoon; (c) Nador Lagoon. 
Benzo[e]Pyrene and Perylene were also investigated but not taken into account in $\sum$ PAHs estimated. Perylene was studied for diagenetic source investigation.

The compounds used as internal standards were perdeuteurated PAHs. Phenanthrened ${ }_{10}$, Anthracene- $d_{10}$, Fluoranthene- $d_{12}$, Chrysene- $d_{12}$, Benzo [a] Pyrened 12 , Benzo[e] Pyrened $_{12}$, and Benzo[ghi]Perylene- $\mathrm{d}_{12}$, were used for quantification (Table 5). Pyrene- $\mathrm{d}_{10}$ and Benzo [b] Fluoranthene$\mathrm{d}_{10}$ were added to the extract injection into the chromatograph, for recovery calculation [12-14].

\subsection{GC-MS Analysis}

The aromatic fraction was analysed by gas chromatography coupled to mass spectrometry (HP-5890 Series II), which was operated under the Selected Ion Monitoring (SIM) mode, using the molecular ions of the studied PAHs (Table 5) (electronic impact at $70 \mathrm{eV}$, interface $290 \mathrm{C}^{\circ}$ ). The oven temperature program used was: $50 \mathrm{C}^{\circ}(2 \mathrm{~min})$ to $290 \mathrm{C}^{\circ}$ (20 $\mathrm{min}$ ) at $5 \mathrm{C}^{\circ} / \mathrm{min}$. The carrier gas was helium at a constant flow rate of $1 \mathrm{ml} / \mathrm{min}$.

The PAHs were quantified relative to perdeuterated PAHs. The response factors of the different compounds were calculated by injecting a Standard Reference Material (NIST, SRM 2260) containing the target PAHs, at certified concentration, and spiked with perdeuterated compounds used as internal standards and those used for recoveries control). The response factor of an analyte (a) relative to internal standard (i) is given by:

$$
\mathrm{K}_{\mathrm{a}}=\left(\mathrm{A}_{\mathrm{i}} / \mathrm{A}_{\mathrm{a}}\right) \times\left(\mathrm{M}_{\mathrm{a}} / \mathrm{M}_{\mathrm{i}}\right)
$$

Where $A_{a}$, and $A_{i}$ indicate the area of the analyte and the internal standard; and $\mathbf{M}_{\mathbf{a}}$, and $\mathbf{M}_{\mathbf{i}}$, the amount of the PAH analyte and the internal standard in the injected solution, respectively.

Recoveries were determined by adding two perdeuterated PAHs, Pyrd 10 and Chrysd $_{12}$, at a known amount to the final extract just before the injection in the chromatograph system. The amounts of the internals standards in the extract are given by:

$$
\mathrm{M}_{\mathrm{i}}=\mathrm{K}_{\mathrm{i}} \times \mathrm{M}_{\mathrm{s}} \times \mathrm{A}_{\mathrm{i}} / \mathrm{A}_{\mathrm{s}}
$$

Where: $\mathbf{K}_{\mathbf{i}}$ is the instrumental response factor of the internals standards relative to perdeuterated PAHs added for recoveries control, $\mathbf{M}_{\mathbf{s}}$ is the amount of PAHs added, and $\mathrm{A}_{i}$, and $\mathrm{A}_{\mathrm{s}}$ refer, respectively, to the areas of the chromatographic peak of the internal standard and the perdeuterated PAHs added for recoveries control in the final extract.

Average recoveries for all samples were $78 \pm 10 \%$. The accuracy of method was estimated by analysing a Certified Reference Materiel (IAEA 417, Organochlorine compounds and petroleum hydrocarbons in sediment sample) at the same conditions as the sediments sampled. It was purchased at the Marine Environment Laboratory of Monaco. Results obtained were within the confidence interval (95\%) (Table 3).

\section{RESULTS AND DISCUSSION}

\subsection{PAHs in Sediments and Organisms}

The results obtained for PAHs concentrations in the selected sediments stations are reported in Table 1. According to the measured levels, the lagoons studied showed a low

Table 1. Results (ng/g dry weight) Obtained in Sediments of Tree Lagoons Studied. ND: Not Detected

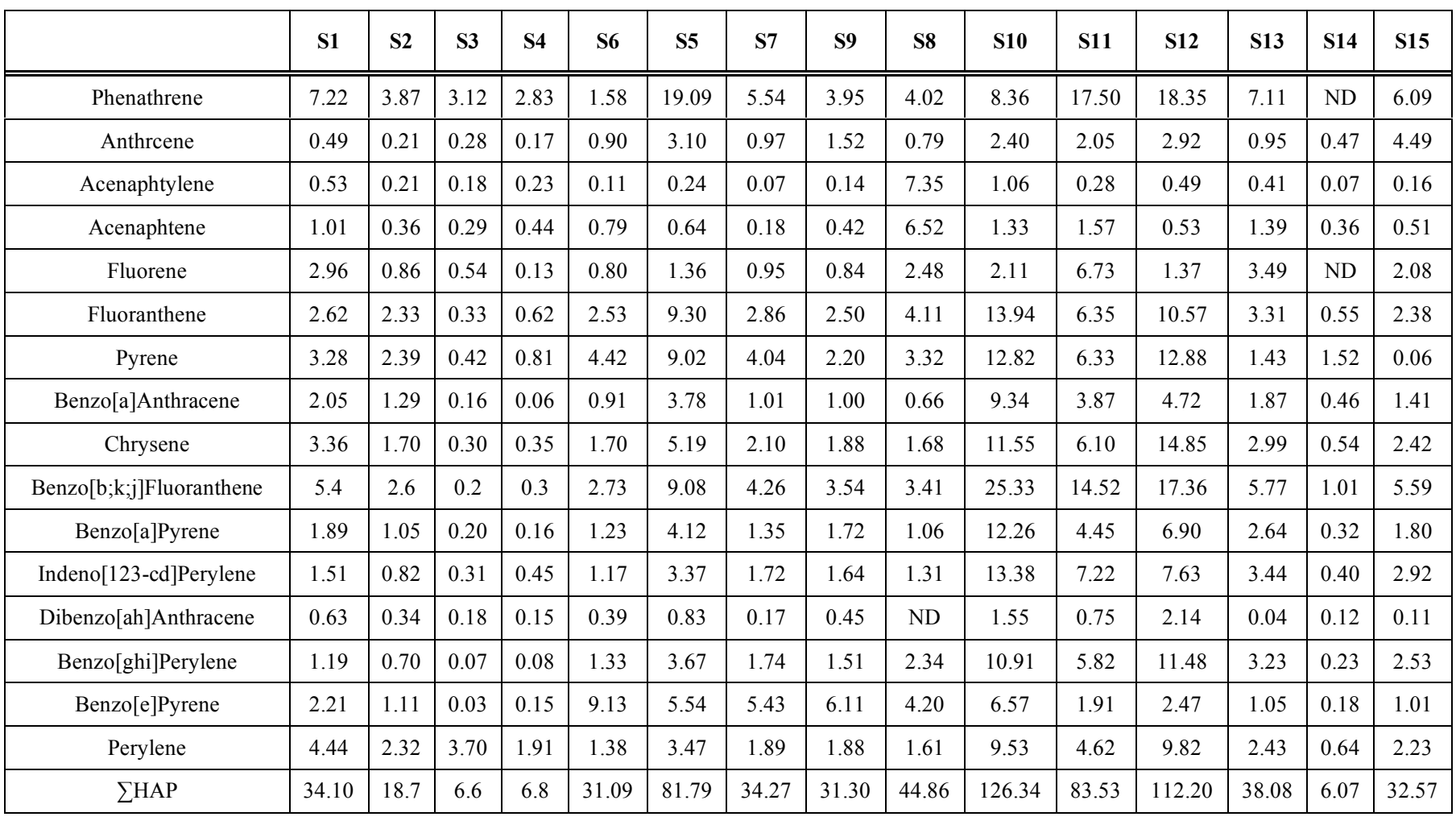


Khnifiss

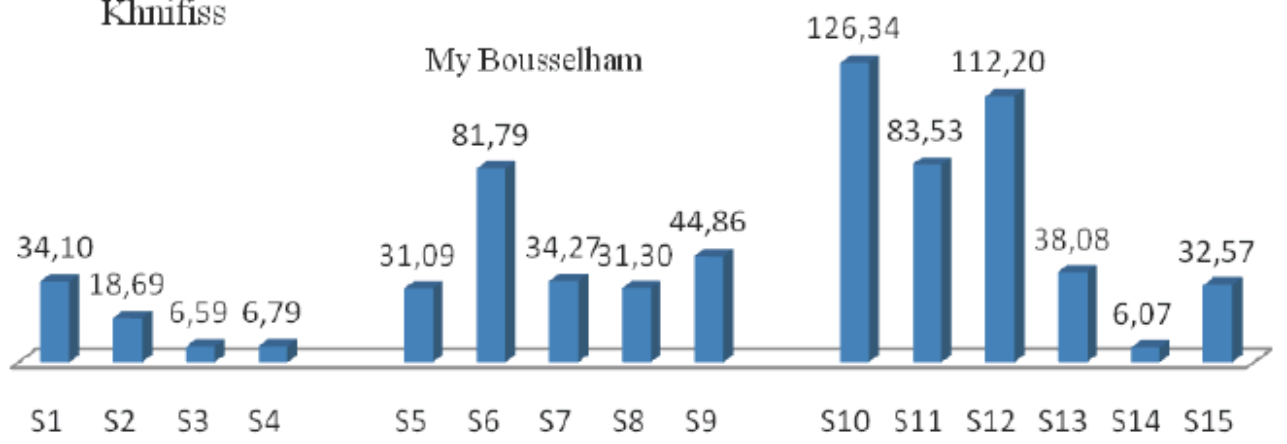

Sampling stations

Fig. (2). Concentrations of PAHs (ng/g dry weight) in sediments, expressed as $\sum P A H$.

to moderate levels of contamination by PAHs. The $\sum$ PAHs concentrations ranged from 6 to $126 \mathrm{ng} / \mathrm{g}$ dry weight, from 31 to $82 \mathrm{ng} / \mathrm{g}$ dry weight and from 6 to $34 \mathrm{ng} / \mathrm{g}$ dry weight for Nador, My Bousselhma and Khnifiss lagoon, respectively. All sampling stations located close to the open sea, exhibit the highest concentrations of PAHs (Fig. 2). A clear dominance of high molecular weight was observed (Pyrene, Chrysene, Benzo [a] Anthracene, Benzo [b;j;k] Fluoranthene, Benzo [a] Pyrene, Benzo[ghi] Perylene) in all sampling sites in respect to low molecular weight (Phenanthrene, Fluorene, Fluoranthene).
Concerning to the Organims, levels obtained (see Table 2) showed low $\Sigma$ PAHs concentrations in most samples analysed. Indeed, all Nador Mussels samples $\sum$ PAHs concentrations were around of $30 \mathrm{ng} / \mathrm{g}$ dry weight, while the Khnifiss Oyster and My Bousselham Clams $\sum$ PAHs concentrations ranged from 7 to $18 \mathrm{ng} / \mathrm{g}$ dry weight and from 28 to 117 ng/g dry weight. This latest moderate $\sum$ PAHs concentration of $117 \mathrm{ng} / \mathrm{g}$ dry weight was observed in Clams of My Bousselham lagoon (C1), sampled in a site where also sediment exhibited the highest $\sum$ PAHs concentration in this lagoon (Fig. 3).

Table 2. Concentrations (ng/g dry weight) Obtained in Organisms of Lagoons Studied. C: Clam; O: Oyster; M: Mussel, ND: Not Detected

\begin{tabular}{|c|c|c|c|c|c|c|c|c|c|c|}
\hline & 01 & $\mathbf{O 2}$ & $\mathbf{O 3}$ & 04 & $\mathrm{C} 2$ & C1 & $\mathrm{C3}$ & M2 & M1 & M3 \\
\hline Phenanthrene & 2.5 & 7.1 & 0.6 & 3.5 & 4.61 & 4.25 & 21.24 & 6.18 & 5.54 & 5.67 \\
\hline Anthracene & 0.3 & 0.8 & 0.1 & 1.5 & 0.34 & 0.46 & 1.73 & 0.51 & 0.24 & 0.13 \\
\hline Acenaphtylene & 0.2 & 0.2 & 0.4 & 0.5 & 0.10 & 0.05 & 1.20 & 0.40 & 0.25 & 0.19 \\
\hline Acenaphtene & ND & ND & 0.5 & 2.0 & ND & ND & 8.23 & 3.91 & ND & ND \\
\hline Fluorene & 1.1 & $\mathrm{ND}$ & 0.8 & 1.2 & 1.18 & ND & 15.25 & 2.75 & 0.72 & 1.23 \\
\hline Fluoranthene & 1.8 & 1.3 & 0.8 & 0.6 & 2.73 & 3.41 & 11.19 & 4.14 & 2.23 & 3.28 \\
\hline Pyrene & 3.3 & 3.1 & 1.5 & 1.1 & 5.85 & 4.57 & 50.83 & 8.22 & 3.15 & 6.47 \\
\hline Benzo[a]Anthracene & 0.4 & 0.8 & 1.0 & 0.7 & 0.69 & 0.30 & 0.25 & 1.37 & 0.43 & 1.17 \\
\hline chrysene & 0.6 & 1.4 & 1.2 & 0.9 & 0.75 & 0.94 & 0.32 & 4.79 & 2.85 & 3.34 \\
\hline Benzo $[\mathrm{b} ; \mathrm{j} ; \mathrm{k}]$ Fluoranthene & 1.7 & 0.8 & 0.3 & 2.7 & 1.86 & 21.27 & ND & 3.22 & 13.52 & 2.51 \\
\hline Benzo[a]Pyrene & 2.7 & 1.2 & ND & 1.7 & 6.00 & 6.31 & 2.50 & 6.01 & 6.83 & 7.32 \\
\hline Indeno[123-cd]Pyrene & 0.4 & 0.5 & 0.2 & 4.3 & 0.60 & 0.54 & ND & 0.35 & 0.05 & 0.20 \\
\hline Dibenzo[ah]Anthracene & 0.9 & ND & ND & ND & ND & ND & 0.09 & 0.53 & 0.21 & 0.15 \\
\hline Benzo[ghi]Perylene & 1.2 & $\mathrm{ND}$ & ND & ND & 0.95 & 9.60 & 2.23 & 0.70 & ND & 0.44 \\
\hline Benzo[e]Pyrene & ND & 0.9 & 0.1 & 0.4 & 2.48 & 1.41 & ND & 1.56 & ND & ND \\
\hline Perylene & 1.0 & ND & 0.3 & 1.4 & 0.37 & ND & 2.32 & 0.54 & ND & 0.31 \\
\hline$\sum \mathrm{PAH}$ & 17.10 & 17.2 & 7.41 & 18.50 & 28.50 & 53.12 & 117.39 & 33.47 & 32.45 & 24.45 \\
\hline
\end{tabular}




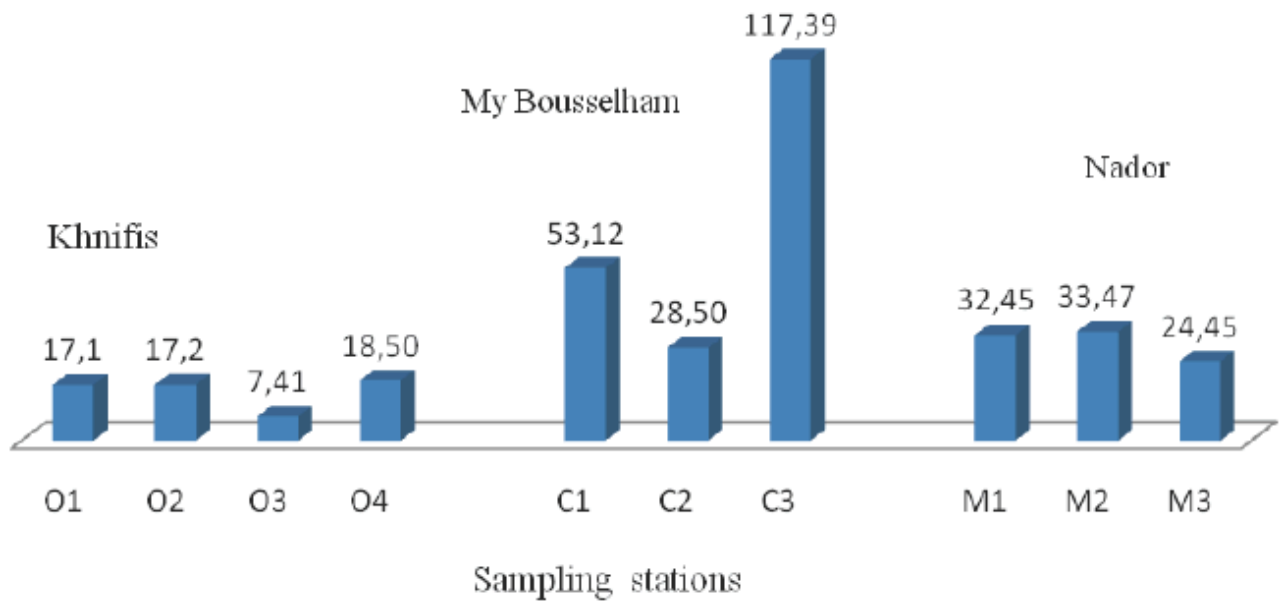

Fig. (3). Concentrations of PAHs (ng/g dry weight) in organisms, expressed as $\sum \mathrm{PAH}$.

Table 3. Comparison of the Obtained (O.V.) and Certified Values (C.V.), in ng/g Dry Weight, for the Analysis of the IAEA-417 Certified Reference Material

\begin{tabular}{|c|c|c|c|c|c|c|c|c|c|c|c|c|c|c|c|c|}
\hline & Phe & An & Acy & Ace & $\mathbf{F}$ & Fl & Pyr & $\mathbf{B}[\mathbf{a}] \mathbf{A}$ & $\mathbf{B}[\mathbf{b}] \mathbf{F}$ & $\mathbf{B}[\mathbf{k}] \mathbf{F}$ & $B[e] P$ & $\mathbf{B}[\mathbf{a}] \mathbf{P}$ & Perylene & IP & $\mathbf{D}[\mathbf{a h}] \mathbf{A}$ & BP \\
\hline $\mathrm{O} . \mathrm{V}$ & 626 & 965 & 41 & 221 & 297 & 6186 & 4902 & 3346 & 3959 & 2514 & 2669 & 3203 & 1520 & 3304 & 553 & 2599 \\
\hline
\end{tabular}

Grouping polycyclic aromatics compounds into different classes depending on the number of aromatic rings present in their structure (Fig. 4), it can be observed that the PAHs with 4-rings are the most abundant in sediments of Nador lagoon and the PAHs with 4,5-rings in My Bousselham lagoon sediment, while the sediments of Khnifiss was dominated by the PAHs with 3,4-rings. This evidence suggests that PAHs sediments contamination in these ecosystems might be originated mainly from pyrolytic process [15]. When it comes to organisms, in general, these marines organisms uptake the low molecular weight HAPs and the most soluble [16, 17]. According to our study, in general, the results showed that the PAHs with 4-rings are the abundant PAHs in all organi- sms analysed. The same result was observed concerning the profile of PAHs accumulation by clams of Ganzirri lagoon [18]. Also, as it can be observed, PAHs with 6-rings are more abundant in Clams than the others organisms (Mussels and Oysters). Indeed, all are filter feeder's and are exposed to suspended and soluble matter, but clams due to its localisation in sediments, are more exposed to PAHs from resuspended particles issues from sediment, enriched in general of heaviest aromatic compounds.

Concerning the concentrations of $\mathrm{B}[\mathrm{a}] \mathrm{P}$, in organism samples, all of them (expressed in $\mathrm{ng} / \mathrm{g}$ dry weight) are below the values established by the European Regulation,

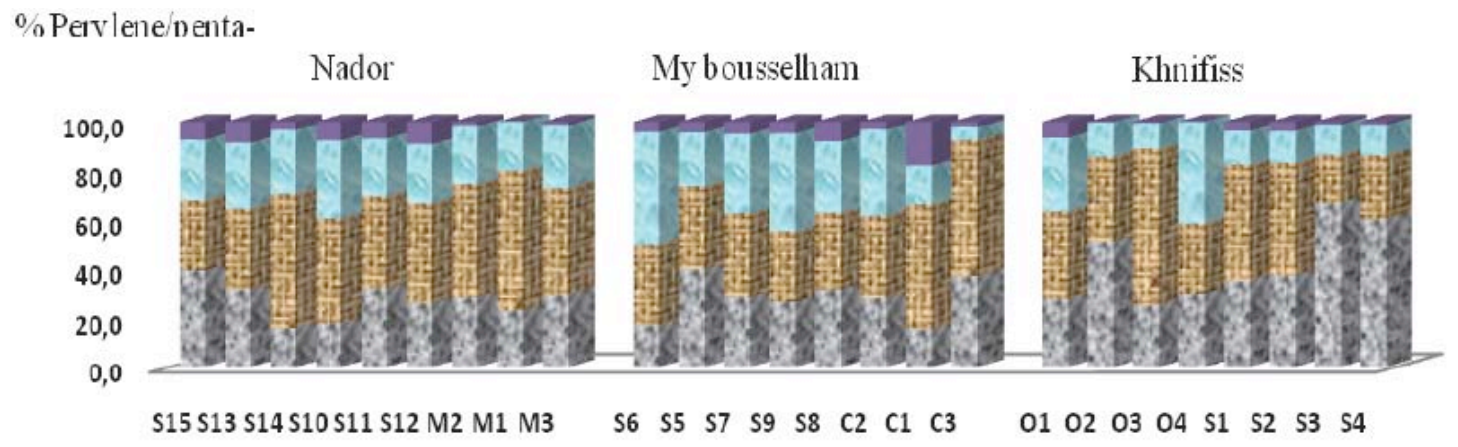

Samnling stations

n\%TR। $=\%$ TETRA $\approx \%$ PENTA $\square \%$ HEXA

Fig. (4). Profile distribution of PAHs per group of aromaticity in sediments and organisms. 
which fixed $10 \mu \mathrm{g} / \mathrm{kg}$ wet weight the maximum admissible in shellfish [19].

In order to make a view of the contamination level by PAHs measured in these Moroccan's lagoons, a Comparison to other lagoons was made of by others studies [18, 20-22], showed that the Moroccans lagoons are slightly contaminated by these compounds, and our results are quiet similar to those obtained in Lessina and Varano lagoons in Italy [23].

\subsection{Sources of PAHs}

In an attempt to identify sources of the PAHs measured in sediments of this study, a source analysis was undertaken. Several molecular ratios, such as Phe/An, Fl/Pyr, Chrys/ $\mathrm{B}$ [a]A have been developed for interpreting PAH composition and identifying possible sources [8, 24-27].

Bicego [28] used the following four PAHs isomer pair ratios to identify possible sources in sediments of the Santos and Sao Vicente Estuary of Sao Paulo (Brazil): An/An+Phe; Fl/F1+Pyr; B[a]A/B[a]A+chry; IP/IP+BP [28]. According to Yunker [8]. When the ratio of $\mathrm{An} / \mathrm{An}+\mathrm{Phe}<0.1$, the PAHs were mainly from petroleum contamination, while it is $>0.1$, PAHs were from combustion source. PAHs with $\mathrm{Fl} / \mathrm{Fl}+\mathrm{Pyr}$ $<0.40$ were from petroleum contamination, while a PAHs with $0.4<\mathrm{Fl} / \mathrm{Fl}+\mathrm{Pyr}<0.5$ were mainly from oil combustion, and PAHs with Fl/F1+Pyr $>0.5$ were from a combustion of coal, wood and grassed matter [8].

Concerning to the $\mathrm{B}[\mathrm{a}] \mathrm{A} / \mathrm{B}[\mathrm{a}] \mathrm{A}+$ chry ratio, PAHs with $0.2<\mathrm{B}[\mathrm{a}] \mathrm{A} / \mathrm{B}[\mathrm{a}] \mathrm{A}+$ chry $<0.35$ could be related to a mixed origin. PAHs with $\mathrm{B}[\mathrm{a}] \mathrm{A} / \mathrm{B}[\mathrm{a}] \mathrm{A}+$ chry $<0.2$ were mainly from petroleum contamination, while PAHs with $\mathrm{B}[\mathrm{a}] \mathrm{A} /$ $\mathrm{B}[\mathrm{a}] \mathrm{A}+$ chry $>0.35$ were from combustion source. Finally, $\mathrm{PAHs}$ with $\mathrm{IP} / \mathrm{IP}+\mathrm{BP}<0.2$ were from petroleum origin input, while PAHs with $0.2<\mathrm{IP} / \mathrm{IP}+\mathrm{BP}<0.5$ were mainly from oil combustion, and IP/IP+BP $>0.5$ were typical of the combustion of coal, wood and grassed matter.
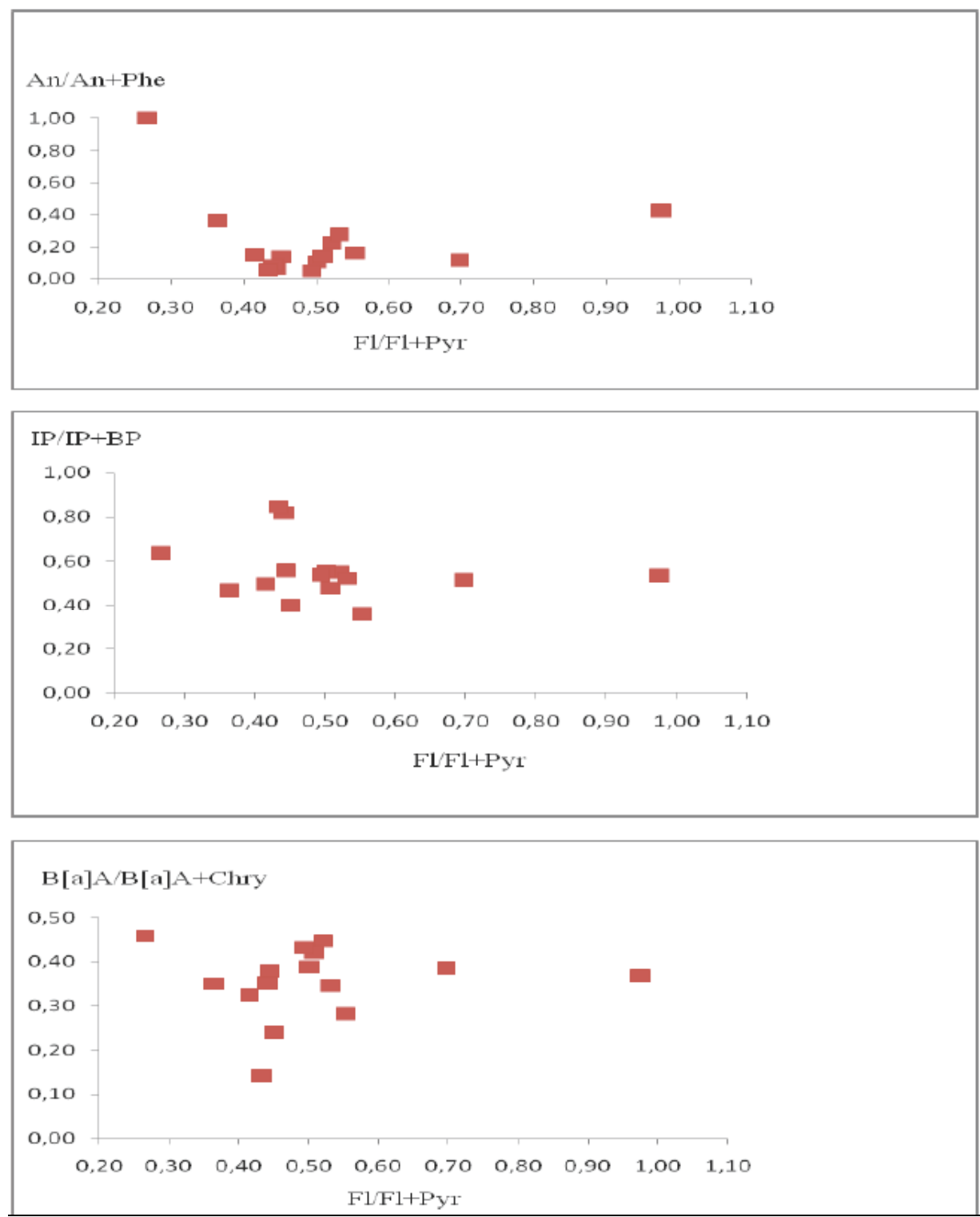

Fig. (5). PAHs cross plots for sediments. Figures show ratios of: (a) IP/IP+B[ghi]P vs.F/F+Pyr; (b) An/An+Phe vs. Fl/F1+Pyr; (c) $\mathrm{vB}[\mathrm{a}] \mathrm{A} / \mathrm{B}[\mathrm{a}] \mathrm{A}+\mathrm{Chry} v s . \mathrm{Fl} / \mathrm{Fl}+\mathrm{Pyr}$. 
These ratios were determined only for sediments lagoons, but organisms weren't concerned by the source study. Indeed, origin study must be limited to sediments, because of possible biotransformation ability of pollutants by organisms, and the PAHs content does not reflect the really fraction that was accumulated [29]. The isomers ratios An/ An+Phe, B[a]A/B(a)A+Chry; IP/IP + BP have been plotted against $\mathrm{Fl} / \mathrm{F} 1+\mathrm{Pyr}$ to show how $\mathrm{PAHs}$ are distributed relative to their source (Fig. 5).

PAHs An/An+Phe values were $>0.1$ for Nador and My bousselham sediments, while it were $<0.1$ for PAHs Khnifiss sediments, showing that PAHs were introduced by combustion and petroleum sources respectively.

PAHs IP/IP+BP values were $>0.5$ for Nador and Khnifiss sediments lagoons, while the ratios values were between 0.2 and 0.5 for Moulay Bousselham sediments lagoon, indicating that the input of PAHs were mainly from coal, wood and grasses and petroleum combustion respectively.

According to the PAHs Fl/Fl+Pyr ratio, PAHs were introduced by the combustion of petrol coal, wood and grasses for both sediments of Nador and Moulay bousselham lagoons, while the combustion of petrol was the main source of PAHs in Khinifiss lagoon sediments.

PAHs B[a]A/B[a]A+Chry exhibit values $>0.35$ for most sediments samples of Nador and Khnifiss, while most sediments of Moulay Bousselhma PAHs B[a]A/B[a]A+Chry were between 0.20 and 0.35 . These results show that PAHs were mainly from combustion source for Nador and Khnifiss lagoons, but were from a mixed source (combustion and petroleum) for Moulay Bousselham lagoon.

As it can be observed, most ratios used in this study pointed to combustion source (oil, coal, grasses and wood), while the petroleum emission source accounts only for Khnifiss lagoon related to $\mathrm{An} / \mathrm{An}+\mathrm{Phe}$ values. Moreover, restriction to the $\mathrm{F} 1 / \mathrm{Fl}+\mathrm{Pyr}$ and $\mathrm{IP} / \mathrm{IP}+\mathrm{BP}$ ratios, showed that PAHs in Nador lagoon were typically from the combustion of coal, grasses and wood, while in case of the others lagoons, PAHs were from petroleum combustion and the

$\%$ of Perylene/Penta-aromatics combustion of coal, grasses and wood. This could be easily justified by the fact that, the surrounding areas of Nador lagoon are more urbanised, with untreated urban waters wastes discharged directly.

Concerning others lagoons less urbanised, where the petroleum combustion is also a prevalent source, the traffic of motors boats often contributes to the pollution lead of these areas.

Moreover, in this study, Perylene was observed to be present at high concentrations in most of the sediments analysed. This compound could be introduced in the aquatic environment by pyrolytic and fossil fuel such as petroleum and by degradation of biogenic precursors (diagenetic origin). This latter source can be predominant in older core sections of anoxic sediment [30], and Perylene is probably the most important diagenetic $\mathrm{PAH}$ encountered in sediments. To investigate this diagenetic source, calculations of relative concentration of this compound, relative to the concentration of the penta-aromatic were done, and ranged from 43 to $75 \%$, from 51 to $69 \%$, and from 8.5 to $15 \%$ for Khnifiss, My Bousselham and Nador lagoons, respectively were done (Fig. 6). This high occurrence of Perylene, especially in sediments of Khnifiss and My Bousselham, the atlantic lagoons, could be attributed to natural source (diagenetic source).

\section{COMPARISON BETWEEN SEDIMENTS AND ORGANISMS: CASE OF MY BOUSSELHAM LAGOON}

In order to make a comparison between PAHs accumulated by organisms and sediments, we have chosen only the case of My Bousselham Lagoon, where organisms and sediments were sampled at the same locations. $\sum$ PAHs concentrations in clams has been plotted versus the $\sum$ PAHs concentrations in sediments, showing a very low correlation $\left(\mathrm{R}^{2}=0.038\right)$. PAHs are hydrophobic compound, and as for the others hydrophobic contaminants (PCB, Pesticides), their accumulation by organisms has been shown to be governed by several factors, such as the lipids content [31], physicals and chemicals parameters of the environment (Turbidity,

My Bousselham

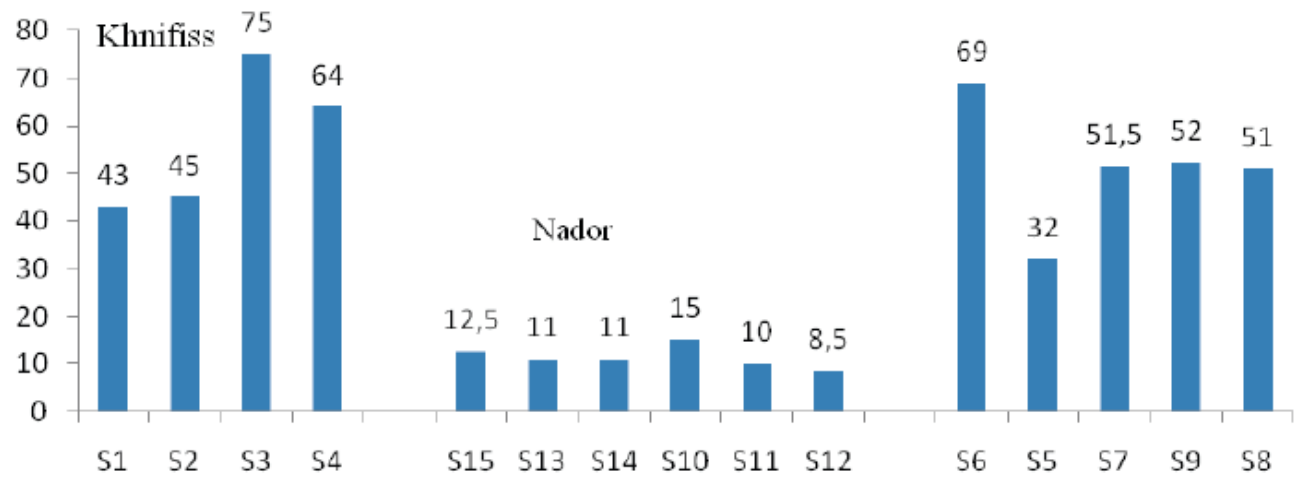

Sampling stations

Fig. (6). $\%$ of concentrations of Perylene relative to Penta-aromatics PAHs. 
Salinity, Temperature...), localisation of the organism (column water, bottom), and the bioavailability of the contaminant [30]. Concerning to the sediments or particles, the concentration of the organic matter could help to determine the characteristics of the hydrocarbons adsorption [32], so that we could predict their availability in column water. High concentration of organic carbon in the sediments is known to reduce the bioavailability of PAHs adsorbed on particles [33].

Table 4. Correlations Values of PAHs between Sediments and Organisms of My Bousselham Lagoon

\begin{tabular}{|c|c|c|}
\hline Compound & $\mathbf{R}^{\mathbf{2}}$ & Correlation \\
\hline \hline Phenanthrene & 0.101761 & Low \\
\hline Anthracene & 0.164836 & Low \\
\hline Acenaphtylene & 0.5041 & Moderate \\
\hline Acenaphtene & 0.944784 & High \\
\hline Fluorene & 0.105625 & Low \\
\hline Flouranthene & 0.157609 & Low \\
\hline Pyrene & 0.334084 & Low \\
\hline Benzo[a]Anthracene & 0.189225 & Low \\
\hline Chrysene & 0.436921 & Moderate \\
\hline Benzo[b;k;j]Fluoranthene & 0.906304 & High \\
\hline Benzo[a]Pyrene & 0.281961 & Low \\
\hline Indeno[123-cd]Pyrene & 0.035721 & Low \\
\hline Dibenzo[a.h]Anthracenen & 0.571536 & Moderate \\
\hline B[ghi]Perylene & 1 & High \\
\hline Pérylene & 0.702244 & High \\
\hline B(e)Pyrene & 0.178929 & Low \\
\hline & & \\
\hline & & \\
\hline
\end{tabular}

For a better understanding of the factors affecting PAHs distribution in Clams of this lagoon, we have considered each PAH individually, and have determined the correlation of each PAH between the two matrices studied, using PCA correlation statistical results obtained with ADE-4 statistical program [34], clams and sediments for the tree stations. Tree levels of correlation were obtained (Table 4). The low correlation obtained for Phenanthrene, Anthracene, Fluorene and the Fluoranthene, considered as the most soluble PAHs in water, means that there is no correlation between the distribution of these PAHs in sediments and Clams.

Clams are filter feeder's organisms and live in sediment compartment, but remain close to the surface that the tips of their siphons are exposed. Water and food particles are drawn in through one siphon to the gills where tiny, hair-like cilia move the water, and the food is caught in mucus on the gills. From there, the food-mucus mixture is transported along a groove to the palps which push it into the clam's mouth. The second siphon carries away the water. The gills also draw oxygen from the water flow. Consequently they are submitted to the pollution adsorbed on particles and also to the dissolved pollution in water column. The lack of correlation between sediments and clams of these compounds, suppose that were assimilated trough the gills, the principal way for the absorption of dissolved compounds, while the high correlation of the distribution of Benzo [ghi] Perylene, Perylene, the Benzo $[\mathrm{b} ; \mathrm{j} ; \mathrm{k}]$ Fluoranthene, the heavier molecular weight and the less soluble PAHs, could suggest that were absorbed through the digestive system.

Table 5. Studied PAHs and the Corresponding Molecular Ions and Internals Standards Used for Quantification

\begin{tabular}{|c|c|c|c|}
\hline PAH studied & $\mathbf{m} / \mathbf{z}$ & Relative internal standard & $\mathbf{m} / \mathbf{z}$ \\
\hline \hline Acenaphtene & 154 & Phenanthrene- $\mathrm{d}_{10}$ & 188 \\
Acenaphtylene & 156 & Phenanthrene- $\mathrm{d}_{10}$ & 188 \\
Fluorene & 166 & Phenanthrene- $\mathrm{d}_{10}$ & 188 \\
Phenanthrene & 178 & Phenanthrene-d $\mathrm{d}_{10}$ & 188 \\
Anthracene & 178 & Anthracene- $\mathrm{d}_{10}$ & 188 \\
Fluoranthene & 202 & Fluoranthene-d $\mathrm{d}_{12}$ & 212 \\
Pyrene & 202 & Fluoranthene-d & 212 \\
Chrysene & 228 & Chrysene- $\mathrm{d}_{12}$ & 240 \\
Benzo[a]Anthracene & 228 & Chrysene- $\mathrm{d}_{12}$ & 240 \\
Benzo[b;k;j]Pyrene & 252 & Benzo[e]Pyrene- $\mathrm{d}_{12}$ & 264 \\
Benzo[a]Pyrene & 252 & Benzo[e]Pyrene- $\mathrm{d}_{12}$ & 264 \\
Perylene & 252 & Benzo[e]Pyrene- $\mathrm{d}_{12}$ & 264 \\
Indeno[1.2.3-cd]Pyrene & 276 & Benzo[ghi]Perylene- $\mathrm{d}_{12}$ & 288 \\
Dibenzo[ah]Anthracene & 278 & Benzo[ghi]Perylene- $\mathrm{d}_{12}$ & 288 \\
Benzo[ghi]Perylene & 276 & Benzo[ghi]Perylene- $\mathrm{d}_{12}$ & 288 \\
\hline
\end{tabular}

The high correlation obtained for Perylene could be explained also by the fact that, the major fraction is introduced by diagenetic process in sediments, and the fraction accumulated of this PAH by Clams was probably absorbed from sediment. The low correlation also obtained for Benzo[e] Pyrene, colud be explained, as reported by Baumard et al., [29], this PAH could obtained by a partial depletion of its isomer the Benzo[a] Pyrene in Mussels, due to metabolic biotransformation. The metabolite obtained is more hydrophilic. Baumard et al., studied the correlation distribution between sediments and Mussels sampled of a Mediterranean French coastal zones, and a moderate correlation $(<$ to 0.6$)$ for heavier PAHs was observed [29], while in our case, correlation was high and reached a value of $\mathrm{R}^{2}$ around 0.9 . This could be explained by the difference location of Mussels (Rocks) and Clams (Bottom). Indeed, organisms living in or near by bottom sediments, could be more exposed to particles matter, enriched in general by heavier molecular weight organics xenobiotics.

\section{CONCLUSIONS}

The results of this study have confirmed the presence of these compounds in sediments and organisms analysed of these tree coastal ecosystems. The high concentrations of PAHs in sediments and organisms were observed in My Bousselham Lagoon, but could remain, from an eco-toxicological point of view, as low levels of pollution comparing to others lagoons investigations. The PAHs detected are originating mainly from the combustion process at higher temperature of the organic matter for My Bousselham and Nador Lagoons, while the combustion of petroleum products 
were the main source of these compounds in Khnifiss Lagoon. Some diagenetic source of Perylene was observed, especially in both Atlantic Lagoons.

The PAHs distribution patterns were different for sediments and similar for organisms. In Atlantic Lagoons, the 4-rings and the 5-rings, the 4-ring and the tri-rings were the dominant groups in sediment respectively of $\mathrm{My}$ Bousselham and Khnifiss Lagoons, while the 4-ring compounds were dominant in the other Mediterranean Lagoon sediments. Concerning organisms, the 4-ring compounds were dominant in My Bousselham and Nador Lagoons, but in Khnifiss Lagoon there was no obvious dominance.

Correlation study between sediments and Clams of My Bousselham Lagoon, showed low correlation for low molecular weight and most soluble PAHs (Phenanthrene, Anthracene, Flourene and Flouranthene), suggesting that they were absorbed as dissolved compounds. A high correlation was observed concerning the heavier molecular weight and the less soluble PAHs (Benzo[ghi]Perylene, Perylene, the Benzo $[\mathrm{b} ; \mathrm{j} ; \mathrm{k}]$ Fluoranthene), suggesting their absorption via particulate matter.

\section{CONFLICT OF INTEREST}

None declared.

\section{ACKNOWLEDGEMENTS}

We thank all members of LPTC laboratory of the University of Bordeaux 1, for their assistance in samples analysis. Also members of cartography laboratory of the National Institute of Halieutic Research (INRH) are thanked.

\section{REFERENCES}

[1] NRC. Oil in the sea inputs, fates, and effects. National Academy Press, Washington DC, 1985.

[2] Lehr RE, Jerina DM. Metabolic activation of polycyclics hydrocarbons. Arch Toxicol 1977; 39: 1-6.

[3] Juhasz AL, Naidu R. Bioremediation of high molecular weight polycyclic aromatic hydrocarbons: a review of the microbial degradation of the Benzo(a)Pyrene. Int Biodeter Biodegr 2000; 45: 57-88.

[4] Chiou CT. Partition and adsorption of organics contaminants in environmental systems. Wiley Interscience, New Jersey, 2002.

[5] Gschwend PM, Hites RA. Fluxes of polycyclic aromatic hydrocarbons to marine and lacustrine sediments in the Northtastern, United States. Geochim Cosmochim Acta 1981; 45: 2359-267.

[6] Colombo JP, Pelletier E, Brochu C, Khalil M, Catoggio JA. Determination of hydrocarbons sources using n-alkanes and polycyclic aromatics distribution indexes. Case study: Rio de la Plata, Argentina. Environ Sci Technol 1988; 23: 888-94.

[7] Budzinski H, Jones I, Bellocq J, Pie'rard C, Garrigues P. Evaluation of sediment contamination by polycyclic aromatic hydrocarbons in the Girond estuary. Mar Chem 1997; 58: 85-97.

[8] Yunker MB, Macdonald RW, Vingarzan R, Mitchell H, Goyette D, Sylvestre. PAHs in the Fraser river bassin: a critical appraisal of $\mathrm{PAH}$ ratios as indicators of PAH source and composition. Org Geochem 2002; 33: 489-515.

[9] Farrington JW, Goldberg ED, Risegrough RW, Martin JH, Bowen VT. US "Mussel Watch" 1976-1978: An overview of the tracemetal, DDE, PCB, hydrocarbon and artificial radionuclide data. Envir Sci Technol 1983; 17: 490-6.

[10] Claisse D, Joanny M, Quintin JY. Le Réseau National d'Observation de la qualité du milieu Marin (RNO). Analysis 1992; 20: M19-M22.
[11] O'Connor TP. Trends in chemical concentrations in mussels and oysters collected along the US coast from 1986 to 1993, Mar Environ Res 1996; 41: 183.

[12] Budzinski H, Papineau A, Baumard P, Garrigues P. Extraction assistée par chauffage micro onde focalisés (MOF) à pression ambiante des composés organiques dans les matrices naturelles: application à l'analyse des composés aromatiques. CR Acad Sci 1995; 321: 69-76.

[13] Budzinski H, Baumard P, Papineau A, Wise S, Garrigues P. Focused microwave assisted extraction of polycyclic aromatic compounds from standard reference materiel, sediment and biological tissues. Proceeding of the 15th International Symposium on Polyaromatic Hydrocarbons, 1995, Belgirate, Italy.

[14] Lettelier M, Budzinski H, Garrigues P, Wise S. Focused microwave assisted extraction of polycyclic aromatic hydrocarbons in open cell from from standard reference materials, (sediment, soil, air particulate). S.A. Special publication of SIJ 1997; 13: 7180 .

[15] Witt G, Trost E. Polycylic aromatic hydrocarbons (PAHs) in sediments of the Baltic sea and of the German coastal waters Chemosphere 1999; 38: 1603-14.

[16] Hellou J, Upshall C, Payne, JF, Naidu S, Paranjape MM. Total unsaturated compounds and polycyclic aromatic hydrocarbons in molluscs collected from waters around Newfoundland. Arch Environ Contam Toxicol 1993; 24: 249-57.

[17] Djomo JE, Garrigues P, Narbonne JF. Uptake and depuration of polycyclic aromatics hydrocarbons from sediments by the zebrafish (Bracydanio rerio). Environ Toxicol Chem 1996; 15: 1177-81.

[18] Gianguzza A, Mannino MR, Olivo A, Orecchio S. Occurence and concentration of PAHs in Clams and sediments of marine coastal lagoon of Ganziri (Italy). Extraction and GC-MS analysis distribution and source. Fresenius Environ Bull 2006; 15: 1023-30.

[19] Perugini M, Visciano P, Giammariono A, Manera M, Di Nardo W, Amorena M. Polycyclic aromatic hydrocarbons in marine organisms from the Adriatic Sea, Italy. Chemosphere 2007; 66: 1904-10.

[20] Mzoughi N, Hellal F, Dachraoui M,Villeneuve JP, Cattini C, De Mora SJ. Méthodologie de l'extraction des hydrocarbures aromatiques polycycliques. Application à des sédiments de la lagune de Bizerte (Tunisie). C.R. Géoscience 2002; 334: 893-901.

[21] Culotta L, De Stefano C, Gianguzza A, Mannino M R, Orecchio S. The PAH composition of surface sediments from Stagnone coastal lagoon. Mar Chem 2006; 99: 117-27.

[22] Perra G, Renzi M, Guerranti C, Focardi SE. Polycyclic Aromatic Hydrocarbons pollution in sediments: Distribution and sources in a lagoon system (Orbetello, Central Italy). Transit. Waters Bull 2009; 3: $45-8$.

[23] Specchiulli A, Renzi R, Perra G, et al. Distribution and sources of Polycyclic Aromatic Hydrocarbons (PAHs) in surface sediments of some Italian lagoons exploited for aquaculture and fishing activities. Int J Environ Anal Chem 2011; 91: 367-86.

[24] Gotz, R, Bauer O.H, Friesel P, Roch K. Organic trace compounds in the water of the river Elbe near Hamburg. Chemosphere 1998; 36: 2103-18.

[25] Soclo HH, Garrigues PH, Ewald M. Origin of polycyclic aromatic hydrocarbons (PAHs) in coastal marine sediments: case studies in Cotonou (Benin) and Aquitaine (France) areas. Mar Pollut 2000; 40: 387-96.

[26] Kavouras IG, Koutrakis P, Tsapakis M, et al. Source apportionment of urban particulate aliphatic and polynuclear aromatic hydrocarbons(PAHs) using multivariate methods. Environ Sci Technol 2001; 35: 2288-94.

[27] Doong RA, Lin YT. Characterisation and distribution of polycyclic aromatic hydrocarbon contamination in surface sediment and water from Gao-Ping River, Taiwan. Water Res 2004; 38: 1733-44.

[28] Bicego MC, Taniguchi S, Yogui GT, et al. Assessment of contamination by polychlorinated biphenyls and aliphatic and aromatic hydrocarbons in sediment of the Santos and Sao Vicente estuary system, Sao Paulo, Brazil. Mar Poll Bull 2006; 52: 1784832.

[29] Baumard P. Biogéochimie des composes aromatiques dans l'environnement marin. Thesis of University of Bordeaux 1, French. 1997.

[30] Venkatesan MI. Occurrence and possible source of perylene in marine sediment-a review. Mar Chem 1988; 25: 1-27. 
[31] Livingstone DR. Persistent pollutants in marine invertebrates. In Persistent Pollutants in Marine Ecosystems, Eds.Walker C.H. and Livingstone, D.R., Oxford, Pergamon Press Ltd. SETAC Special Publications Series. La Point, TW 1992.

[32] Means JC, Hassett JJ, Wood SG, Banwart WL. Sorption properties of energy-related pollutants and sediments. In: Jones P. Leber, Ed. Polynuclear Aromatic Hydrocarbons. Ann Arbor Science publishers, Ann Arbor, Mich 1979; pp. 327.
[33] Boese BL, Winsor M, Lee II H, Echols S, Pelletier J, Randall R. PCB congeners and hexachlorobenzene biota sediment accumulation factors for Macona Nasuta exposed to sediments with different total carbon organic contents. Environ Toxicol Chem 1995; 14: 303-10.

[34] ADE4 2004. Ecological Data Analysis: Exploratory and Euclidean methods in Environmental Sciences. Available from: http:// pbil.univ-lyon1.fr/ADE-4-old/ADE-4/.html

Received: May 26, 2011

Revised: July 1, 2011

Accepted: July 8, 2011

(C) Semlali et al.; Licensee Bentham Open.

This is an open access article licensed under the terms of the Creative Commons Attribution Non-Commercial License (http://creativecommons.org/licenses/by$\mathrm{nc} / 3.0 /)$, which permits unrestricted, non-commercial use, distribution and reproduction in any medium, provided the work is properly cited. 